Check for updates

Cite this: RSC Adv., 2021, 11, 33809

Received 19th August 2021

Accepted 10th October 2021

DOI: 10.1039/d1ra06279d

rsc.li/rsc-advances

\title{
DIBALH: from known fundamental to an unusual reaction; chemoselective partial reduction of tertiary amides in the presence of esters $\uparrow$
}

\author{
Yu Jin Heo, Hyun Tae Kim, Ashok Kumar Jaladi and Duk Keun An (D)*
}

\begin{abstract}
This study presents a quick and reliable approach to the chemoselective partial reduction of tertiary amides to aldehydes in the presence of readily reducible ester groups using commercial DIBALH reagent. Moreover, the developed method was also extended to multi-functional molecules bearing ester moieties, which were successfully chemoselectively reduced to the corresponding aldehydes.
\end{abstract}

\section{Introduction}

Chemoselectivity, the preferential transformation of one of two or more functional groups that are present in a molecule or reactant, can be a useful method for protecting-group-free synthesis of complex natural products or other materials. ${ }^{1}$ Although several reagents and catalysts have been reported as suitable for chemoselective functional group manipulations, the conversion of relatively less reactive functional groups in the presence of readily reacting ones is highly interesting and uncommon.

The partial reduction of amides to aldehydes ${ }^{2,3}$ in the presence of ester groups is one of the best examples for such transformations. Even though the reduction of amides to alcohols or amines has been known for several years, ${ }^{4}$ only a limited number of reagents have been hitherto reported for partial reduction of amides to aldehydes in the presence of esters.

For example, Hwu and co-workers ${ }^{5}$ reported on a system for selective reduction of aliphatic amides using alkyltrifluoromethanesulphonate and L-Selectride, giving the corresponding aldehydes in moderate yields. Recently, the Schwartz $\left(\mathrm{Cp}_{2} \mathrm{Zr}(\mathrm{H}) \mathrm{Cl}\right)$ reagent $^{6}$ and in situ-prepared Schwartz reagents ${ }^{7}$ showed promising results in the selective reduction of amides to aldehydes. However, these reagents are highly expensive and sensitive to long-term storage. ${ }^{6 c-e}$

A magnesium-based borohydride system was reported by Singaram and co-workers ${ }^{8}$ for the selective reduction of Weinreb amides. However, this system requires additional steps to obtain the desired aldehyde. More recently, Adolfsson and coworkers reported the use of a catalytic hydrosilylation system with TMDS/ $\left(\mathrm{Mo}(\mathrm{CO})_{6}\right)$ for the selective reduction of amides. ${ }^{9}$ Nevertheless, this reaction afforded a mixture of products from

Department of Chemistry, Institute for Molecular Science and FusionTechnology, Kangwon National University, Chunchon 24341, Republic of Korea. E-mail: dkan@ kangwon.ac.kr

$\dagger$ Electronic supplementary information (ESI) available. See DOI: 10.1039/d1ra06279d aliphatic amides containing $\alpha$-hydrogens. Both of these reported systems involve highly expensive, sensitive reagents and possess practical difficulties such as limitations to either aromatic or aliphatic substrates. In order to overcome the difficulties encountered in previous methods, it is crucial to develop a more efficient and readily available reagent that would participate in the selective reduction of amides to aldehydes over esters.

The reduction of amides with DIBALH and reagents derived from DIBALH is a known reaction..$^{10}$ Previous reports on the reduction of amides with DIBALH at $0{ }^{\circ} \mathrm{C}$ or room temperature resulted in a mixture of aldehydes, alcohols, and amines. ${ }^{11}$ Considering the information available on the modification of DIBALH and Red-Al reagents utilized in the partial reduction of various carbonyl and acid derivatives, ${ }^{12}$ in this study we observed the chemoselective reduction of tertiary amides such as Weinreb and morpholine amides to the corresponding aldehydes in the presence of esters with commercial DIBALH (Scheme 1).

\section{Results and discussion}

Initially, we carried out a comparative study on the partial reduction of esters and tertiary amides with DIBALH in various

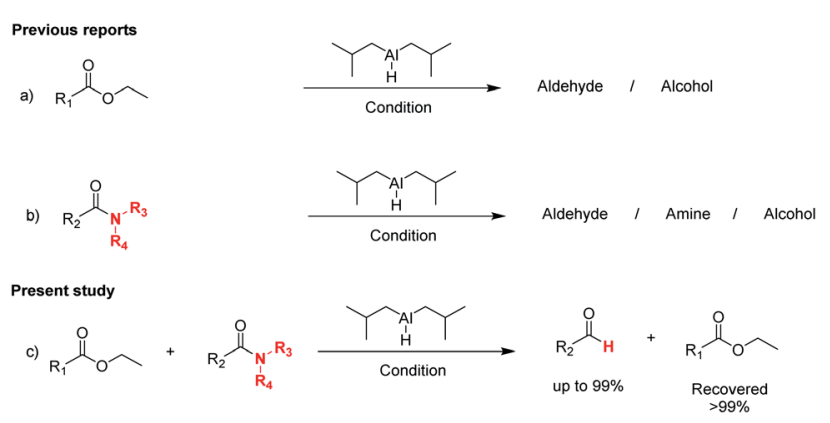

Scheme 1 DIBALH mediated reductions of esters and tertiary amides. 
View Article Online

RSC Advances

Paper

Table 1 Reaction conditions for the chemoselective partial reduction of tertiary amides in the presence of esters

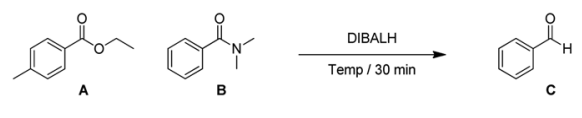

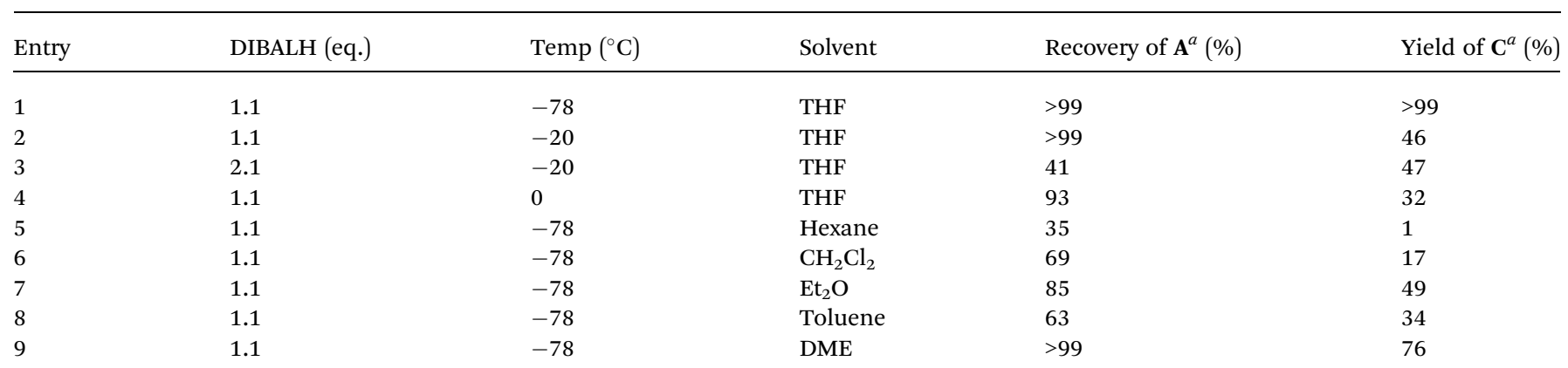

${ }^{a}$ Yields were determined by GC.

Table 2 Reduction of various N,N-dimethyl amides in the presence of the ethyl benzoate ${ }^{a}$

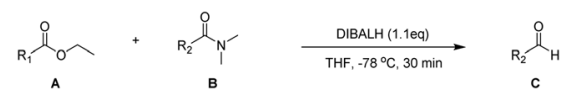

Substrate

Entry

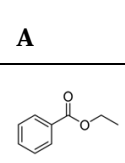

2

3

1
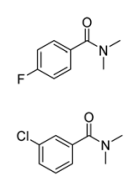

$>99$

$>99$

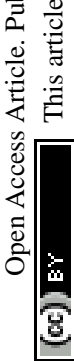

(

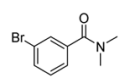

$>99$

$>99$

4

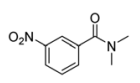

$>99$

$>99$

5

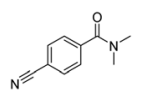

$>99$

91

6

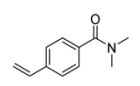

$>99$

$97^{f}$
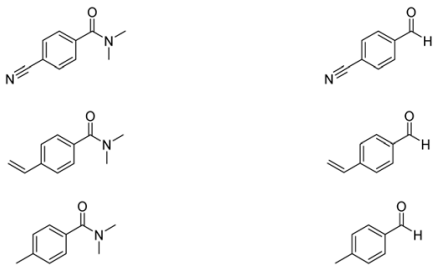

$>99$

$86^{f}$

7

8
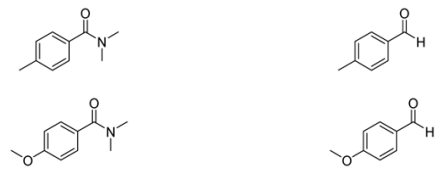

$>99$

$>99^{c}$

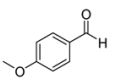

$>99$

$82^{d}$

9
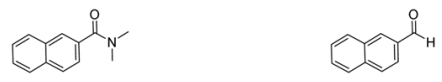

$>99$

$>99$

10
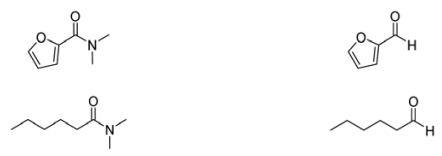

$>99$

$71^{e}$

11

12

th i

$+x_{5}$

$>99$

$78^{e}$

$>99$

$70^{f}$
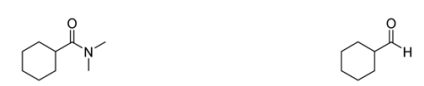

$>99$

$56^{g}$

${ }^{a}$ Reaction condition: DIBALH : substrate $(1.1: 1.0),-78{ }^{\circ} \mathrm{C}, 30 \mathrm{~min} .{ }^{b}$ Yields were determined by GC. ${ }^{c}$ Reaction time was 1 h. ${ }^{d}$ Equivalents of substrate $:$ DIBALH $=1: 1.2$. ${ }^{e}$ Equivalents of substrate $:$ DIBALH $=1: 1.4 .{ }^{f}$ Equivalents of substrate $:$ DIBALH $=1: 1.7 .{ }^{g}$ Equivalents of substrate : DIBALH $=1: 1.5$.

33810 | RSC Adv., 2021, 11, 33809-33813

(c) 2021 The Authors). Published by the Royal Society of Chemistry 
solvents. The reactions were performed in THF, hexane, $\mathrm{Et}_{2} \mathrm{O}$, $\mathrm{CH}_{2} \mathrm{Cl}_{2}$, toluene, and DME. While the amide reduction in hexane was almost inert (entry 5 in Table 1), the reaction in DME resulted in a good yield (76\%) with high chemoselectivity (entry 9 in Table 1). Notably, the reaction in THF at $-78{ }^{\circ} \mathrm{C}$ gave the aldehyde in almost quantitative yield (entry 1 in Table 1), while at -20 and $0{ }^{\circ} \mathrm{C}$ only $46 \%$ and $32 \%$ yields, respectively, were obtained (entries 2 and 4 in Table 1). Additionally, the reactions in ether and toluene afforded lower aldehyde yield with moderate chemoselectivity (entries 7 and 8 in Table 1).

After successfully attaining the selective reduction of tertiary amides in the presence of esters in THF, we applied the respective conditions to the partial reduction of various $\mathrm{N}, \mathrm{N}$ dimethyl amides to the corresponding aldehydes. As shown in Table 2, N,N-dimethyl amides were reduced to aldehydes in the presence of ethyl benzoate. Aromatic compounds with electrondonating and withdrawing groups afforded excellent to quantitative yields of the corresponding aldehydes (entries 1-8 in Table 2). Polyaromatic compound, 2-naphthylamide, resulted in the partial reduction to aldehyde with quantitative yield (entry 9 in Table 2). Additionally, we tested the reaction on a heteroaromatic amide (2-furamide), aliphatic amides (hexanamide and decanamide), and an alicyclic amide (cyclohexanecarboxamide). These substrates yielded the corresponding aldehydes in moderate to good yields (56-78\%) with good chemoselectivity (entries 10-13 in Table 2). Next, various $N, N$ dimethyl amides were reduced to the corresponding aldehydes in the presence of esters bearing electron-donating and withdrawing groups, as well as an aliphatic ester (Table 3). Irrespective of the nature of the amide substituents, most amides underwent a smooth partial reduction, thereby giving the corresponding aldehydes in quantitative yields. Whereas, aliphatic $N, N$-dimethyl amides, gave relatively good yields (78-80\%, entries 4, 8, 12 in Table 3).

After achieving the selective reduction of $N, N$-dimethyl amides to aldehydes, we turned our attention to the partial reduction of Weinreb and morpholine amides in the presence of various esters. As shown in Table 4, the reduction of both aromatic and aliphatic amides proceeded smoothly to give the corresponding aldehydes in quantitative yields with good chemoselectivity.

Table 3 Reduction of $\mathrm{N}, \mathrm{N}$-dimethyl amides in the presence of various esters ${ }^{a}$

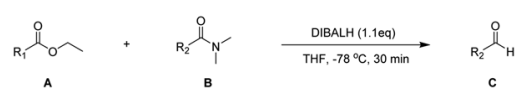

\begin{tabular}{|c|c|c|c|c|c|}
\hline \multirow[b]{2}{*}{ Entry } & \multicolumn{2}{|c|}{ Substrate } & \multirow[b]{2}{*}{ Product $\mathbf{C}$} & \multirow[b]{2}{*}{ Recovery of $\mathbf{A}^{b}(\%)$} & \multirow[b]{2}{*}{ Yield of $\mathbf{C}^{b}(\%)$} \\
\hline & $\mathbf{A}$ & $\mathbf{B}$ & & & \\
\hline 1 & & & & $>99$ & $>99$ \\
\hline 2 & & & & $>99$ & $>99$ \\
\hline 3 & & & & $>99$ & $>99^{c}$ \\
\hline 4 & & & & $>99$ & $78^{d}$ \\
\hline 5 & & & & $>99$ & $>99$ \\
\hline 6 & & & & $>99$ & $>99$ \\
\hline 7 & & & & $>99$ & $>99^{c}$ \\
\hline 8 & & & & $>99$ & $78^{d}$ \\
\hline 9 & & & & 90 & $>99$ \\
\hline 10 & & & & 92 & $>99$ \\
\hline 11 & & & & 80 & $>99^{e}$ \\
\hline 12 & & & & 81 & $80^{d}$ \\
\hline
\end{tabular}

${ }^{a}$ Reaction condition: DIBALH : substrate $(1.1: 1.0),-78{ }^{\circ} \mathrm{C}, 30 \mathrm{~min} .{ }^{b}$ Yields were determined by GC. ${ }^{c}$ Reaction time was 1 hour. ${ }^{d}$ Equivalents of substrate $:$ DIBALH $=1: 1.4 .{ }^{e}$ Equivalents of substrate $:$ DIBALH $=1: 1.2$. 
Table 4 Reduction of various tertiary amides in the presence of esters

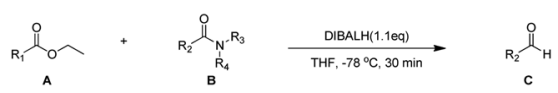

\section{Substrate}

\begin{tabular}{|c|c|c|c|c|c|}
\hline Entry & $\mathbf{A}$ & B & Product $\mathbf{C}$ & Recovery of $\mathbf{A}^{a}(\%)$ & Yield of $\mathbf{C}^{a}(\%)$ \\
\hline 1 & & & & $>99$ & $>99$ \\
\hline 2 & & & & $>99$ & $>99$ \\
\hline 3 & & & & $>99$ & $>99$ \\
\hline 4 & & & & $>99$ & $>99$ \\
\hline 5 & & & & $>99$ & $>99$ \\
\hline 6 & & & & $>99$ & $>99$ \\
\hline
\end{tabular}

In order to further investigate the chemoselectivity of the present method, we extended it to the multi-functional organic compounds (Table 5). Accordingly, aromatic $N, N$-dimethyl amide, morpholine amide, and Weinreb amides containing ester moiety were treated with DIBALH and successive chemoselective reduction was afforded from amide groups leaving esters unreactive in most cases (entries 1-3 in Table 5). Additionally, aliphatic amides with ester groups were converted to aldehydes in good yields (entries 4 and 5 in Table 5).

Table 5 Chemoselective reduction of multi-functionalized compounds

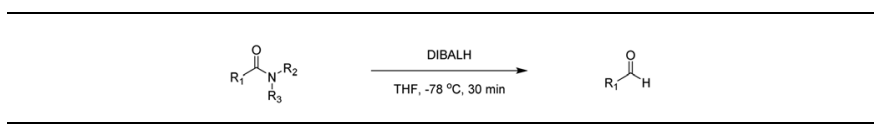

Entry Substrate DIBALH (eq.) Product $\quad$ Yield of product ${ }^{a}(\%)$

1

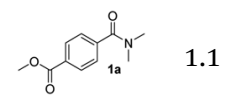

2

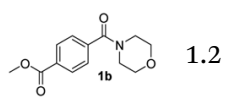

3

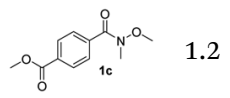

4

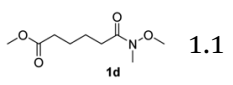

5 的
${ }^{a}$ Yields were determined by GC. ${ }^{b}$ Reaction time is $1 \mathrm{~h}$. The parentheses were isolated yields after silica column chromatography.

\section{Conclusions}

In summary, in this study we have identified an unusual approach for the chemoselective partial reduction of various tertiary amides ( $N, N$-dimethyl, Weinreb, and morpholine amides) to the corresponding aldehydes in the presence of the relatively more reactive ester groups using commercial DIBALH. Among the tested solvents, THF afforded the best results in terms of chemoselectivity and quantitative conversions. In addition, multi-functional organic compounds also yielded desired aldehydes in the presence of readily reducible ester groups. Therefore, the present method is providing a simple and economically benign protocol for the preparation of aldehydes used in complex syntheses.

\section{Conflicts of interest}

There are no conflicts of interest to declare.

\section{Acknowledgements}

This study was supported by the National Research Foundation of Korea (NRF) grant funded by the Korean Government (MSIT) (2021R1F1A1047825).

\section{Notes and references}

1 (a) R. W. Hoffmann, Synthesis, 2006, 3531-3541; (b) P. S. Baran, T. J. Maimone and J. M. Richter, Nature, 2007, 446, 404; (c) I. S. Young and P. S. Baran, Nat. Chem., 2009, 1, 193-205.

2 R. C. Larock, Comprehensive Organic Transformations: A Guide to Functional Group Preparation, VCH, New York, 1989. 
3 (a) S. Bower, K. Kreutzer and S. L. Buchwald, Angew. Chem., Int. Ed. Engl., 1996, 35, 1515-1516; (b) S. Nahm and S. M. Weinreb, Tetrahedron Lett., 1981, 22, 3815-3818; (c) H. C. Brown and A. J. Tsukamoto, J. Am. Chem. Soc., 1959, 81, 502-503; (d) B. Soto-Cairoli, J. Justo de Pomar and J. A. Soderquist, Org. Lett., 2008, 10, 333-336; (e) C. Douat, A. Heitz, J. Martinez and J. A. Fehrentz, Tetrahedron Lett., 2000, 41, 37-40; $(f)$ G. Wittig and P. Hornberger, Ann. Chim., 1952, 577, 11; (g) J. S. Cha, S. E. Lee, H. S. Lee, J. C. Lee, J. M. Kim, O. O. Kwon and S. J. Min, Bull. Korean Chem. Soc., 1992, 13, 338-339; (h) S. Laval, W. Dayoub, A. Favre-Reguillon, P. Demonchaux, G. Mignani and M. Lemaire, Tetrahedron Lett., 2010, 51, 2092-2094; (i) C. L. Bailey, A. Y. Joh, Z. Q. Hurley, C. L. Anderson and B. Singaram, J. Org. Chem., 2016, 81, 3619-3628; (j) G. Godjoian and B. Singaram, Tetrahedron Lett., 1997, 38, 1717-1720.

4 (a) V. M. Micovic and M. L. Mihailovic, J. Org. Chem., 1953, 18, 1190-1200; (b) R. F. Nystrom and W. G. Brown, J. Am. Chem. Soc., 1948, 70, 3738-3740.

5 S.-C. Tsay, J. A. Robl and J. R. Hwu, J. Chem. Soc., Perkin Trans. 1, 1990, 757-759.

6 (a) P. C. Wailes and H. Weigold, J. Organomet. Chem., 1970, 24, 405-411; (b) B. Kautzner, P. C. Wailes and H. Weigold, J. Chem. Soc., Chem. Commun., 1969, 1105; (c) Y. Zhao and V. Snieckus, Org. Lett., 2014, 16, 390-393; (d) P. Wipf and C. Kendall, Top. Organomet. Chem., 2005, 8, 1; (e) P. Wipf and H. Jahn, Tetrahedron, 1996, 52, 12853-12910.

7 (a) J. M. White, A. R. Tunoori and G. I. Georg, J. Am. Chem. Soc., 2000, 122, 11995-11996; (b) J. T. Spletstoser,
J. M. White, A. R. Tunoori and G. I. Georg, J. Am. Chem. Soc., 2007, 129, 3408-3419; (c) Y. Zhao and V. Snieckus, Org. Lett., 2014, 16, 390-393; (d) Z. Huang and E. Negishi, Org. Lett., 2006, 8, 3675-3678.

8 C. L. Bailey, J. W. Clary, C. Tansakul, L. Klabunde, C. L. Anderson, A. Y. Joh, A. T. Lill, N. Peer, R. Braslau and B. Singaram, Tetrahedron Lett., 2015, 56, 706-709.

9 F. Tinnis, A. Volkov, T. Slagbrand and H. Adolfsson, Angew. Chem., Int. Ed., 2016, 55, 4562-4566.

10 (a) H. C. Brown and A. J. Tsukamoto, J. Am. Chem. Soc., 1964, 86, 1089; (b) K. Sunggak and A. J. Hyo, J. Org. Chem., 1984, 49, 1717-1724; (c) J. H. Ha, J. H. Ahn and D. K. An, Bull. Korean Chem. Soc., 2006, 27, 121-122; (d) J. S. Cha, J. C. Lee, H. S. Lee and S. E. Lee, Tetrahedron Lett., 1991, 32, 6903-6904; (e) S. H. Im, W. K. Shin, A. K. Jaladi and D. K. An, Tetrahedron Lett., 2018, 59, 2335-2340; (f) J. Y. Kim, W. K. Shin, A. K. Jaladi and D. K. An, Tetrahedron, 2018, 74, 42364241; $(g)$ J. S. An, W. K. Shin and D. K. An, Bull. Korean Chem. Soc., 2015, 36, 2928-2931.

11 M. Hudlicky, Reductions in Organic Chemistry, Ellis Horwood Limited, Chichester, 1984, pp. 164-171.

12 (a) Y. R. Kim and D. K. An, Bull. Korean Chem. Soc., 2012, 33, 4194-4196; (b) Y. M. Choi, M. E. Kim and D. K. An, Bull. Korean Chem. Soc., 2009, 30, 2825-2826; (c) J. H. Ahn, J. I. Song, J. E. Ahn and D. K. An, Bull. Korean Chem. Soc., 2005, 26, 377-378; (d) S. M. Woo, M. E. Kim and D. K. An, Bull. Korean Chem. Soc., 2006, 27, 1913-1914; (e) M. S. Kim, Y. M. Choi and D. K. An, Tetrahedron Lett., 2007, 48, 50615064; (f) J. I. Song and D. K. An, Chem. Lett., 2007, 36, 886887. 